\title{
A STUDY OF IDENTIFYING SUCCESS VARIABLES FOR CONSTRUCTION PARTNERING VIA SEM FRAMEWORK
}

\author{
Tung-Tsan Chen \\ Department of Construction Engineering, National Quemoy University, No. 1 University Rd., Jinning Township, Kinmen, \\ Taiwan 892, R.O.C, tungtsan@kmit.edu.tw \\ Chih-Han Kao \\ Department of Construction Engineering, National Quemoy University, No. 1 University Rd., Jinning Township, Kinmen, \\ Taiwan 892, R.O.C
}

Follow this and additional works at: https://jmstt.ntou.edu.tw/journal

Part of the Civil and Environmental Engineering Commons

\section{Recommended Citation}

Chen, Tung-Tsan and Kao, Chih-Han (2010) "A STUDY OF IDENTIFYING SUCCESS VARIABLES FOR CONSTRUCTION PARTNERING VIA SEM FRAMEWORK," Journal of Marine Science and Technology. Vol. 18: Iss. 5, Article 1.

DOI: $10.51400 / 2709-6998.1898$

Available at: https://jmstt.ntou.edu.tw/journal/vol18/iss5/1

This Research Article is brought to you for free and open access by Journal of Marine Science and Technology. It has been accepted for inclusion in Journal of Marine Science and Technology by an authorized editor of Journal of Marine Science and Technology. 


\section{A STUDY OF IDENTIFYING SUCCESS VARIABLES FOR CONSTRUCTION PARTNERING VIA SEM FRAMEWORK}

\section{Acknowledgements}

The authors special thanks go to all survey participants and reviewers of the paper, and appreciate the National Science Council of the Republic of China, Taiwan for financially supporting the research (NSC94 -2211-E-507-001). 


\title{
A STUDY OF IDENTIFYING SUCCESS VARIABLES FOR CONSTRUCTION PARTNERING VIA SEM FRAMEWORK
}

\author{
Tung-Tsan Chen* and Chih-Han Kao*
}

Key words: construction partnership, structural equation model, success variable.

\begin{abstract}
Owners and contractors in construction partnerships cooperate to quickly achieve results with reduced start-up costs, achieve a win-win result for both parties, increase efficiency, and reduce the possibility of conflict in construction projects. This study explored success variables (SVs) in construction partnerships via a novel framework. A questionnaire survey was distributed to experienced practitioners in the Taiwan construction industry. Factor analysis was applied to extract SVs based on the questionnaire results. Structural equation modeling (SEM) was then used to verify the relationships between the SVs identified in construction partnership. The analytical results showed that four success factors (SFs) in construction partnerships (collaborative team culture, long-term quality perspective, consistent objectives, and resource sharing) are closely linked. Success in construction partnership is most strongly influenced by the relationship between collaborative team culture and consistent objectives, while the relationship between collaborative team culture and long-term quality perspective is least significant. Therefore, failure of partnering in construction projects can be minimized and success can be achieved by carefully managing the four SFs.
\end{abstract}

\section{INTRODUCTION}

A constant lack of trust and verification of information has characterized the working relationship between owners, designers, contractors and materials providers in the Taiwan construction industry. Owners continually seek the lowest cost contractors. In response to perceived exploitation by owners, contractors (professionals) gradually become less loyal and less trustworthy. Changing contractors not only creates risk but also consumes time and effort and may compromise qual-

Paper submitted 06/02/09; revised 07/19/09; accepted 08/19/09. Author for correspondence: Tung-Tsan Chen (e-mail: tungtsan@kmit.edu.tw).

*Department of Construction Engineering, National Quemoy University, No. 1 University Rd., Jinning Township, Kinmen, Taiwan 892, R.O.C. ity. Thus, the practice of partnering between owners and contractors is steadily growing.

Construction projects rely on the efficient organization at all levels of the teams involved, including the owners themselves, architects, engineers, contractors and materials providers. Notably, although the ability, experience, professional knowledge and skill of these teams is directed toward completing the project, the teams are still independent bodies with their own objectives, goals and management styles. In traditional construction contracts, each team involved in a project acts independently, which frequently causes communication and co-operation problems that impact production and efficiency. The addition of other problems in the construction industry such as disappointing final results, excessive supervision, wasted effort [29], wasted time and money, and poor team morale and communication can all cause cost overruns and project delays, which can then lead to conflicts and lawsuits. This process demonstrates the difficulty of operating and managing construction projects.

The construction industry has undergone a remarkable transformation during the past decade [29], due to changes including increased competition, improved quality, decreased costs of construction materials and equipment, globalization, delayed enactment of laws, rapidly changing technology and construction methods, increased need for rapid and flexible solutions to construction problems and increased risk in construction contracts. These changes represent a crisis in the construction industry, and companies have begun to explore alternative management methods to maintain superiority. Partnering can achieve quick and efficient results via low start-up costs [30]. Additional advantages of partnering include risk sharing, cooperative problem solving, competitive advantages increasing, safe assets, new markets exploiting, and productivity enhancing. In the 1990s, the construction industry focused on providing superior service [14]. Ensuring client satisfaction is important for the success of any company. To achieve firm goals and avoid competition, firms must devise partnering strategies to increase and maintain competitive advantages. Consequently, researchers and practitioners have proposed various construction project success factors $[3,8-10$, $16]$. 
This study conducts a questionnaire survey of construction industry professionals to further analyze the construction partnership variables. These questionnaires compare the roles of different professionals in construction projects and the effects of their various project attributes which provide a reference for partnerships in the industry. Moreover, this study also probes the success variables in construction partnering and explores their relationship by structural equation modeling (SEM). The study also analyzes cause and effect factors and linear structural relations.

\section{RESEARCH APPROACH}

To achieve the research objective, the following methodologies were developed. First, metrics were developed to measure success attributes among project partnership variables. Metrics for project partnership variables were then developed, and a questionnaire survey was conducted to measure success attributes among project partnership variables.

The SPSS 10.0 software package was used for statistical analysis of the data collected from the questionnaires, and the results were presented by frequency, percentage and cross analysis. The statistics application software AMOS 5.0 was used for the confirmatory analysis, and overall research framework for this research study shows in Fig. 1.

\section{Questionnaire Development}

The questionnaire used a Likert-type scale from 1 (extremely unimportant) to 5 (extremely important). To identify the questionnaire structure, a second assessment was performed to ensure its credibility and effectiveness. The original questionnaire included twenty-two nominated SVs in construction partnership. Reliability testing was conducted to examine measurement accuracy and also to ensure that characteristics and variables were accurately measured. The measurements were combined with the forecast number of characteristics to represent the correct measurements. Various studies were used as references for the questionnaires in the scale regarding important SVs of partnerships and partner benefits. Cheung et al. and $\mathrm{Li}$ et al. $[11,20]$ were consulted regarding construction project partnerships, and behavioral aspects in construction partnering established the "important factors in partnerships." Li et al. [21] were referenced for co-operation in the construction projects. Additionally, various studies were referenced for project management, project objective, success factors and designed production of "project objectives and important success factors" to match content validity $[1,2,8$, 12].

A pilot test was conducted for validation of the study questionnaire. Thirty six practitioners and scholars involved in the Taiwanese construction industry were asked to complete the questionnaire and comment on its readability, comprehensiveness and precision. Thirty-six copies of the questionnaire were delivered to the intended subjects, and thirty-four copies were retrieved in October, 2005. Cronbach's was used to

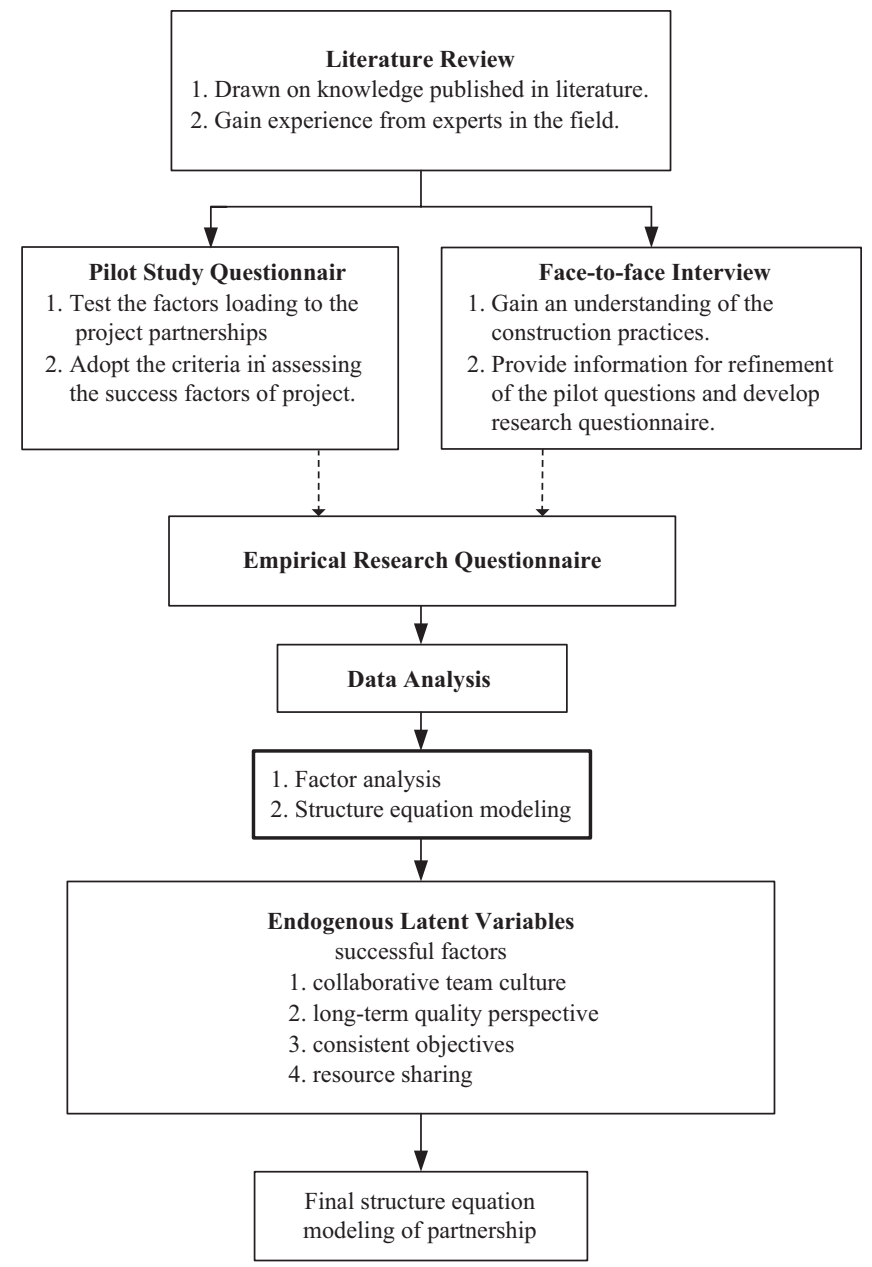

Fig. 1. Overall research framework for this research study.

determine reliability, and all data initially underwent factor analysis. A Cronbach's value was derived for each factor. A with value exceeding 0.9 ; between 0.9 and 0.7 ; and under 0.35 indicated high, acceptable and low reliability, respectively. The reliability scale used in this study had a Cronbach's of 0.904 indicating high reliability of the pilot test questionnaire [15].

\section{Questionnaire Distribution}

The survey population included practitioners and experts in the Taiwan construction industry. The research subjects were drawn from three groups: hi-tech large construction projects (HLCP), non-hi-tech large construction projects (NLCP), and non-hi-tech small construction projects (NSCP). Hi-tech construction projects were large projects requiring highly interfaced integration such as the high speed rail. Non-hi-tech construction projects were those projects without high interface integration, such as roadway construction projects. The questionnaires were distributed via mail, e-mail, fax, telephone and personal delivery to increase the rate of response and sample representation. Three hundred thirty copies of questionnaires were distributed on January, 2006, to construction 
Table 1. Sampling group, profession, and number of subjects.

\begin{tabular}{lrcrr}
\hline Sampling group & HLCP & NLCP & NSCP & Total \\
\hline Government employee & 3 & 22 & 14 & 39 \\
Project owners & 14 & 16 & 2 & 32 \\
Design firm & 4 & 39 & 20 & 63 \\
Construction firm & 29 & 48 & 10 & 87 \\
Total & 50 & 125 & 46 & 221 \\
\hline
\end{tabular}

Note: HLCP stands for hi-tech large construction projects; NLCP stands for non-hi-tech large construction projects; NSCP stands for non-hi-tech small construction projects.

industry subjects. Two hundred twenty-one copies were retrieved (67\% response rate), of which fifty were from the HLCP, 125 were from the NLCP, and forty-sixx were from the NSCP.

By profession, the sample included thirty-nine (17.6\%) government employees, thirty-two (14.5\%) project owner (Taiwan High Speed Rail Corporation; THSRC) workers, sixty-three (28.5\%) design firm workers and eighty-seven (39.4\%) construction firm workers. Of the 221 respondents, 125 (56.6\%) respondents were from the NLCP, fifty $(22.6 \%)$ were from the HLCP, and forty-six (20.8\%) were from the NSCP. Table 1 lists survey subjects by sample group, profession and number.

\section{Extracting Success Factors}

Factor analysis uses a series of methods to identify groups of related variables and is therefore an ideal technique for creating a more easily understood framework [25]. Factor analysis employes a data matrix produced by collecting a number of individual cases or respondents. Principal component analysis is commonly used in factor analysis and involves generating linear combinations of variables through factor analysis so that they explain as much of the variance in the collected data as possible.

This study applied factor analysis to explore the underlying constructs of the SVs for construction partnering. Twenty-two SVs were subjected to factor analysis using principal component analysis and varimax rotation. A matrix was automatically generated along with the factor analysis by using the software SPSS 10.0. Using a combination of the scree plot (Fig. 2) and eigenvalue greater than one rule, nineteen SVs were derived from the twenty-two nominated SVs, and the four-Factor solution was considered the most appropriate. Table 2 presents the results of the varimax rotation.

The goal of factor analysis is inclusive development of initial variables. Hence, an SV load exceeding 0.5 (rounded) on the factor were considered acceptable SVs and left unmodified. Under this criterion, six of the SVs loaded on Factor 1, three of the SVs loaded on Factor 2, five of the SVs loaded on Factor 3 and five of the SVs loaded on Factor 4. Based on an examination of the inherent relationships among the variables under each of the Factors, Table 2 displays the four extracted factors designated collaborative team culture, long-term qual-

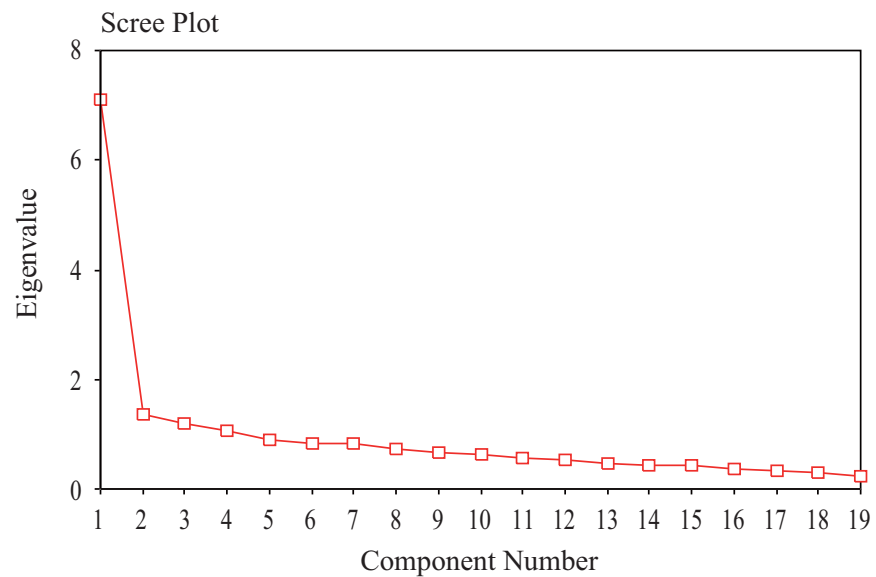

Fig. 2. Total variance associated with each factor.

ity perspective, consistent objectives and resource sharing, respectively.

Collaborative team culture refers to a partnership formation in which, to be effective, each firm must feel free to question any assumption made by any other party. Such an arrangement helps parties to understand the reasoning behind assumptions made and may make the expert party question its own assumptions [19]. Long-term quality perspectives can be considered as the willingness of the involved parties to manage unanticipated problems continuously [4]. More committed parties are expected to balance the attainment of short-term objectives with that of long-term goals and to achieve both individual and joint missions without fearing opportunistic behavior [23]. Consistent objectives in terms of compatible goals are the strategic goals of individual organizations that can converge to achieve the goal of the alliance, bind the organizations together and establish the direction, value and activity of the firm. Partnership failure mainly results from ambiguous goals and poorly coordinated activities [22]. Given effective management, resource sharing can improve the competitiveness and construction capability of partnering relationships. Due to resource scarcity and competition, an organization will otherwise rarely share resources such as technology, experience, information, knowledge, ability, etc., with other organizations [13].

\section{SEM ON CONSTRUCTION PARTNERSHIPS}

\section{SEM Development}

The SEM can be used to describe relationships between two variables: observed and latent. Observed variables represent data that can be directly measured by a researcher such as numeric responses to a rating scale item on a questionnaire. Latent variables, conversely, are variables of interest to a researcher but not directly observable. To observe latent variables, frameworks must therefore be constructed to express latent variables in terms of observed variables. 
Table 2. Principal components analysis on success variables.

\begin{tabular}{|c|c|c|c|c|}
\hline Variables & $\begin{array}{c}\text { Factor } 1 \\
\text { (collaborative team } \\
\text { culture) }\end{array}$ & $\begin{array}{c}\text { Factor } 2 \\
\text { (long-term quality } \\
\text { perspective) }\end{array}$ & $\begin{array}{c}\text { Factor } 3 \\
\text { (consistent objectives) }\end{array}$ & $\begin{array}{c}\text { Factor } 4 \\
\text { (resource sharing) }\end{array}$ \\
\hline SV6 Dedicated team & 0.569 & & & \\
\hline SV7 Flexibility to change & 0.499 & & & \\
\hline SV10 Long-term perspective & 0.467 & & & \\
\hline SV12 Formation at design stage & 0.702 & & & \\
\hline SV13 Good cultural fit & 0.776 & & & \\
\hline SV14 Company wide acceptance & 0.741 & & & \\
\hline SV8 Commitment to quality & & 0.831 & & \\
\hline SV9 Commitment to continuous improvement & & 0.802 & & \\
\hline SV17 Questioning attitudes & & 0.615 & & \\
\hline SV1 Mutual trust & & & 0.677 & \\
\hline SV2 Effective communication & & & 0.487 & \\
\hline SV4 Clear understanding & & & 0.607 & \\
\hline SV5 Acting consistent with objectives & & & 0.567 & \\
\hline SV15 Technical expertise & & & 0.482 & \\
\hline SV3 Commitment from senior management & & & & 0.475 \\
\hline SV11 Total cost perspective & & & & 0.767 \\
\hline SV16 Financial security & & & & 0.643 \\
\hline SV18 Availability of resources & & & & 0.568 \\
\hline SV19 Equal power/empowerment & & & & 0.591 \\
\hline
\end{tabular}

Implementing the SEM involves two procedures: a measurement component and a structural component [7]. The measurement component specifies how latent variables are measured in terms of observed variables. The structural component expresses relationships between latent variables. The SEM enables the development of a causal indicator framework in which a latent theoretical construct of interest is represented by measured variables. The SEM also accounts for measurement errors, thus producing more accurate representations.

This study uses AMOS 5.0 statistical software to develop the SEM framework, which consists of a measurement component and a structural component. The former determines how well exogenous variables measure latent variable constructs. The later models the relationships between latent variable constructs, allowing for explicit modeling of direct, indirect and correlative effects.

\section{SEM Modification}

A basic framework was developed by incorporating the latent constructs with their corresponding measures into an initial SEM on the basis of theoretical expectations and past empirical findings. Framework improvements were performed over several iterations to arrive at a final framework specification by using a combination of modification indices [17] and theoretical justifications until a final satisfactory framework was identified.

Figure 3 shows the initial SEM framework. Additionally, to ensure the appropriateness of groupings of the identified attributes into construction partnership SVs, Cronbach alpha reliability testing was applied. Cronbach alpha values range from 0 to 1 . Values ranging from 0.6 to 0.7 are considered sufficient, and values above 0.7 are considered reliable [27]. As Table 3 displays, all groupings in the initial SEM had Cronbach alpha values higher than 0.7 , indicating sufficient internal consistency of the initial SEM.

Figure 4 shows the final SEM framework. The rectangles indicate observed (or measured) variables. Unobserved latent variable constructs appear in ellipses. The arrows in the figure indicate the direction of hypothesized influence. For example, the influence of the long-term quality perspective $(\eta 2)$ is presumed to be reflected in the observed measures of the variables: commitment to quality (SV8), commitment to continuous improvement (SV9) and questioning attitudes (SV17) as depicted by the directional arrows. Error terms are included for each exogenous variable indicating a latent variable construct. For example, commitment to quality does not perfectly longterm quality perspective, and so an error term is needed to represent the error of measurement. This error term, $\varepsilon 8$, is an unobserved entity consisting of the portion of measured value of commitment to quality (SV8) that does not reflect the influence of long-term quality perspective.

The overall fitness of the initial SEM can be assessed by employing goodness of fit (GOF) indices. In fact, several GOF indices are available to test the fitness of the SEM. If the GOF indices of the initial SEM do not reach the recommended levels, framework refinements are required to improve overall 


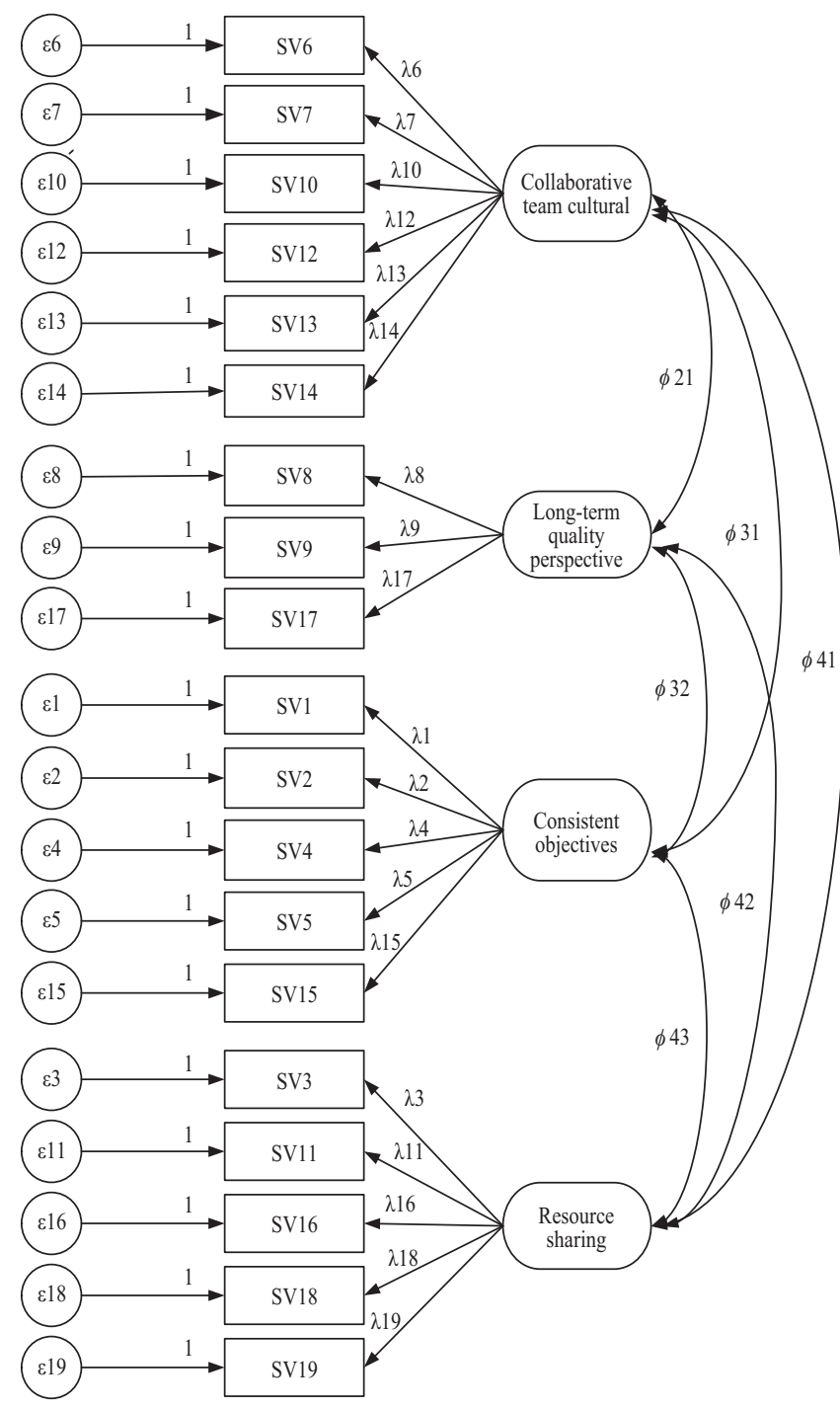

Fig. 3. Initial SEM framework.

fitness. Table 4 displays the recommended levels of the GOF indices. In this study, framework refinements were performed by two methods. First, low correlation paths and associated variables were systematically eliminated [26]. The interrelationship paths were then revised or covariance error paths were added between the variables or latent factors. Both methods were needed to refine the SEM framework with reference to the modification indices provided by the AMOS 5.0 program. After refinement, the framework with the best performance for both GOF and the theoretical expectations was selected as the final SEM framework [24].

\section{Measurement Component of SEM Framework}

The collaborative team culture latent variable (construct) is measured in the SEM framework by team dedication, flexibility to change, long-term perspective, formation at design stage, good cultural fit and company wide acceptance. The good cultural fit had the most influence on collaborative team
Table 3. Reliability testing of initial SEM.

\begin{tabular}{|c|c|c|}
\hline $\begin{array}{c}\text { Factors } \\
\text { (Latent ariables) } \\
(\eta \mathrm{i})\end{array}$ & $\begin{array}{c}\text { Items } \\
\text { (Measuring variables) } \\
(\mathrm{SVi})\end{array}$ & $\begin{array}{c}\text { Chronbach } \\
\alpha \text { value }\end{array}$ \\
\hline $\begin{array}{l}\text { Collaborative } \\
\text { team } \\
\text { culture } \\
(\eta 1)\end{array}$ & $\begin{array}{l}\text { SV6 Dedicated team } \\
\text { SV7 Flexibility to change } \\
\text { SV10 Long-term perspective } \\
\text { SV12 Formation at design stage } \\
\text { SV13 Good cultural fit } \\
\text { SV14 Company wide acceptance }\end{array}$ & 0.8326 \\
\hline $\begin{array}{l}\text { Long-term } \\
\text { Quality } \\
\text { perspective } \\
\text { ( } 2)\end{array}$ & $\begin{array}{l}\text { SV8 Commitment to quality } \\
\text { SV9 Commitment to continuous } \\
\quad \text { improvement } \\
\text { SV17 Questioning attitudes }\end{array}$ & 0.8010 \\
\hline $\begin{array}{l}\text { Consistent } \\
\text { objectives } \\
(\eta 3)\end{array}$ & $\begin{array}{l}\text { SV1 Mutual trust } \\
\text { SV2 Effective communication } \\
\text { SV4 Clear understanding } \\
\text { SV5 Acting consistent with objectives } \\
\text { SV15 Technical expertise }\end{array}$ & 0.7016 \\
\hline $\begin{array}{l}\text { Resource } \\
\text { sharing } \\
(\eta 4)\end{array}$ & $\begin{array}{l}\text { SV3 Commitment from senior } \\
\quad \text { management } \\
\text { SV11 Total cost perspective } \\
\text { SV16 Financial security } \\
\text { SV18 Availability of resources } \\
\text { SV19 Equal power/empowerment }\end{array}$ & 0.7432 \\
\hline
\end{tabular}

culture $(\lambda=0.724)$, followed by team dedication $(\lambda=0.701)$, flexibility to change $(\lambda=0.692)$, company wide acceptance $(\lambda=0.681)$, and long-term perspective $(\lambda=0.470)$. Formation at design stage had the least influence on collaborative team culture $(\lambda=0.397)$. The conflicts influence is minimal because mutual trust, effective communication, full acknowledgement and respect cultivate excellent cultural collaboration and team spirit. Owing to these positive aspects, fewer conflicts and quarrels occur, and a better working environment are established to reach the worthwhile project [28].

The long-term quality perspective latent variable (construct) is measured in the SEM framework by the commitment to quality, commitment to continuous improvement, a questioning attitude, long-term perspective and formation at design stage. The commitment to continuous improvement had the strongest influence in characterizing long-term quality perspective $(\lambda=0.918)$ followed by commitment to quality $(\lambda=$ $0.785)$, questioning attitudes $(\lambda=0.321)$, and long-term perspective $(\lambda=0.279)$. Formation at design stage had the least influence on characterizing long-term quality perspective $(\lambda=$ 0.229 ). The likely explanation is that, as the world modernizes, the construction industry also becomes more versatile, expansive, and complicated, and skills and procedures evolve into new ideas. Additionally, customers demand better quality and durability, increasing the importance of long-term quality. Only through the mutual promise by both sides continuously 


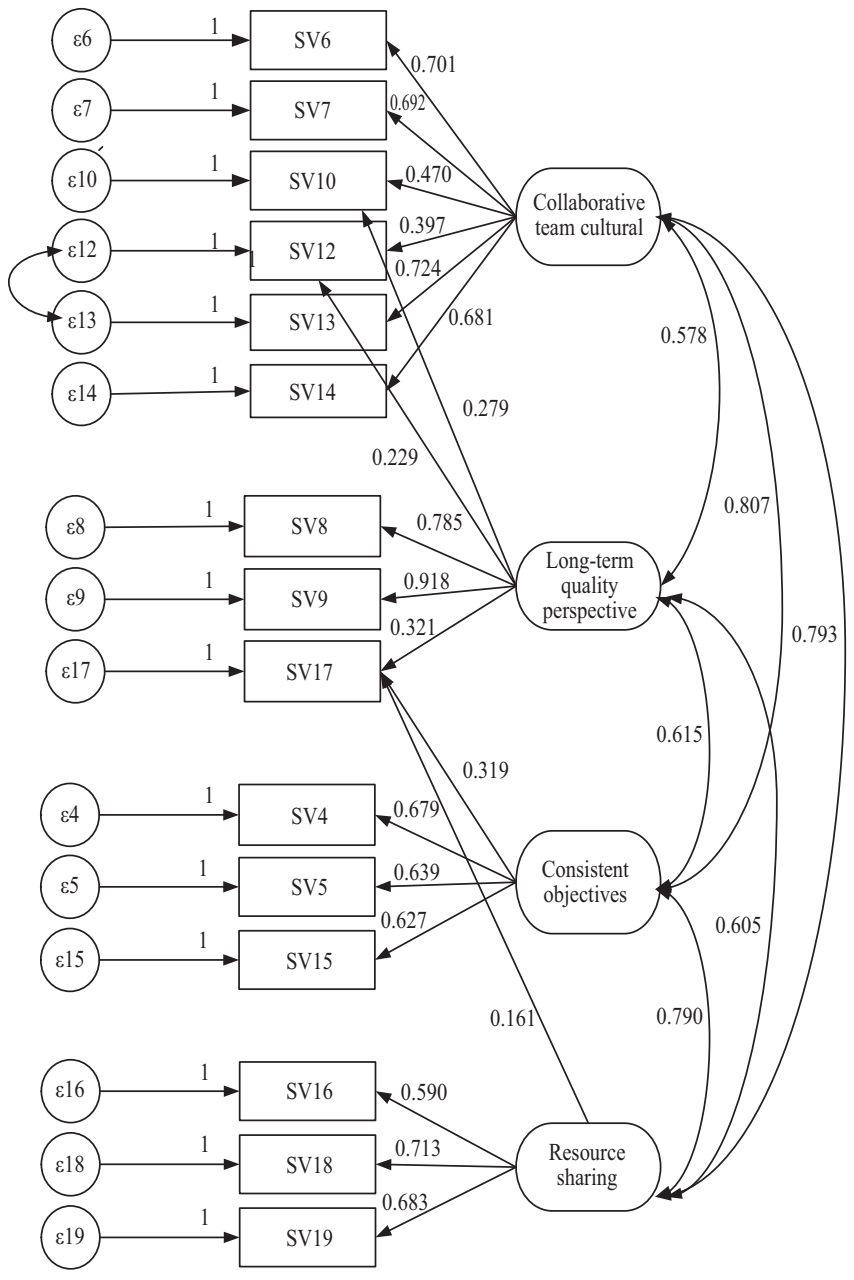

Fig. 4. Finally SEM framework.

improve the partnering arrangement does the project in progress receive care, a quality guarantee and long-term customer satisfaction $[4,10]$.

The consistent objective latent variables (construct) are measured in the SEM framework by clear understanding, acting consistently with objectives, technical expertise and questioning attitudes. Clear understanding had the most influence in characterizing consistent objectives $(\lambda=0.679)$, followed by acting consistently with objectives $(\lambda=0.639)$ and technical expertise $(\lambda=0.627)$. Questioning attitudes had the least influence on characterizing consistent objectives $(\lambda=$ $0.319)$. In partnering, team cooperation is based on collective objectives, actions and ideas. Besides professional knowledge and effective communication, partners require a clear understanding. With these qualities, the team can efficiently achieve the objectives of the project [3].

The resource sharing latent variable (construct) is measured in the SEM framework by financial security, availability of resources, equal power/empowerment and questioning attitudes. Availability of resources had the most influence on resource sharing $(\lambda=0.713)$, followed by equal power/empow-
Table 4. Goodness of fit measurement of the SEM framework.

\begin{tabular}{ccccc}
\hline $\begin{array}{c}\text { Evaluation } \\
\text { index }\end{array}$ & GOF & $\begin{array}{c}\text { Description } \\
\text { of test }\end{array}$ & $\begin{array}{c}\text { Initial } \\
\text { SEM }\end{array}$ & $\begin{array}{c}\text { Final } \\
\text { SEM }\end{array}$ \\
\hline $\begin{array}{c}\text { Absolute } \\
\text { fit }\end{array}$ & Pearson chi-square $\left(\chi^{2}\right)$ & The least & 875.683 & 119.431 \\
index & Dimension of freedom & & 518 & 79 \\
& P value & $>0.05$ & 0.000 & 0.002 \\
& RMR value & $<0.05$ & 0.036 & 0.022 \\
& RMSEA value & $<0.05$ & 0.056 & 0.048 \\
Relative & GFI value & $>0.9$ & 0.811 & 0.936 \\
fit & NFI value & $>0.9$ & 0.747 & 0.915 \\
index & IFI value & $>0.9$ & 0.879 & 0.969 \\
Parsimonious & CFI value & $>0.9$ & 0.877 & 0.969 \\
fit & NCI value & $<3$ & 1.691 & 1.512 \\
index & PNFI value & $>0.5$ & 0.690 & 0.688 \\
& PCFI value & $>0.5$ & 0.810 & 0.729 \\
Cross- & Hoelter CN value & $\geqq 200$ & 150 & 205 \\
validation & Akaike AIC value & The least & 1029.683 & 201.431 \\
\hline
\end{tabular}

Note: deleted consistency objectives attribute: mutual trust, effective communication; deleted resource sharing attribute: commitment from senior management, total cost perspective.

erment $(\lambda=0.683)$ and financial security $(\lambda=0.590)$. Questioning attitudes had the least influence on resource sharing $(\lambda=0.161)$. If none of the parties involved in the project adopt a win-win attitude, self-interest and lack of consideration for others will jeopardize project flow, and resources such as financing, members, materials, machinery and information will not be able to be fully used. Conversely, if resources can be shared and applied fully in partnering, the project will be significantly improved [5, 14].

\section{Structural Component of SEM Framework}

The implication of the initial research framework (Fig. 3) is a linear relationship between the four latent variables (collaborative team culture, long-term quality perspective, consistent objectives, and resource sharing). The highest correlation was observed between collaborative team culture and consistent objectives $(\psi=0.807)$, followed by collaborative team culture and resource sharing $(\psi=0.793)$, consistent objectives and resource sharing $(\psi=0.790)$, long-term quality and consistent objectives $(\psi=0.615)$ and long-term quality perspective and consistent objectives $(\psi=0.605)$. The lowest correlation was between collaborative team culture and longterm quality perspective $(\psi=0.578)$.

This study tested whether or not the structural component of four latent variables fit the data of a sample. According to Bryman and Cramer [6], a correlation below 0.39 is low, and one between 0.49 to 0.69 is modest. In this study, the correlations among the four latent variables, between 0.578 to 0.807 , were moderate. Discriminant validity tests also indicated the 
four latent variables of partnerships were distinct at 95\% possibility [18], indicating they are statistically independent variables.

The above data indicate that for each factor in construction partnering, a very close relationship exists between collaborative team culture and consistent objectives, and there is little relationship between collaborative team culture and long-term quality perspective. Of the four factors observed in the framework, the correlation coefficient of "collaborative team culture" and "long-term quality perspective" exceeded 0.6. Since these four factors strongly affect one another, these four factors and their framework application must be deeply probed to achieve the expected project results via successful partnering.

\section{CONCLUSION}

This paper explored SVs in construction partnerships in Taiwan. Factor analysis was used to analyze the data collected via questionnaire survey and extract nineteen SVs which were classified into four SFs. The most important factor was collaborative team culture, followed by a long-term quality perspective, consistent objectives and resource sharing. The SEM was then used to verify the relationship between these identified SVs and four SFs.

It was found that construction partnership SFs are most strongly influenced by the relationship between collaborative team culture and consistent objectives, while the relationship between collaborative team culture and long-term quality perspective is least significant. It was also found that good cultural fit has the most influence on characterizing collaborative team culture, commitment to continuous improvement has the highest influence in characterizing long-term quality perspective, clear understanding has the highest influence in characterizing consistent objectives, and availability of resource has the highest influence in characterizing resource sharing.

Failure of partnering construction projects can be minimized, and success can be achieved by carefully managing the four SFs. Additionally, project owners, designers, contractors and other related departments who were directly or indirectly involved in this study all significantly influence the success of construction partnering. Consequently, successful construction partnering requires the combined effort of all parties involved. The development of strategies for achieving effective results in management and partnership can prevent conflicts, lawsuits and inefficiency while increasing project efficiency and productivity and achieving a win-win situation for all involved parties.

More research may be needed to determine whether or not the scales used in this study are reliable and valid for measuring other populations of construction partnerships. By using AMOS, multitrait-multimethod confirmatory factor analysis, the scales may be tested for application to different populations of construction partnerships. Additionally, researchers may also explore whether the scales can be used to measure partnership specialization among other groups of partnerships (e.g., Joint Venture, BOT, Turnkey).

\section{ACKNOWLEDGMENTS}

The authors special thanks go to all survey participants and reviewers of the paper, and appreciate the National Science Council of the Republic of China, Taiwan for financially supporting the research (NSC94 -2211-E-507-001).

\section{REFERENCES}

1. Atkinson, R., "Project management: Cost, time and quality, two best guesses and a phenomenon, its time to accept other success criteria," International Journal of Project Management, Vol. 17, No. 6, pp. 1-11 (1999).

2. Belout, A. and Gauvreau, C., "Factors influencing project success: The impact of human resource management," International Journal of Project Management, Vol. 22, No. 1, pp. 1-11 (2004).

3. Black, C., Akintoye, A., and Fitegerald, E., "An analysis of success factors and benefits of partnering in construction," International Journal of Project Management, Vol. 18, No. 6, pp. 423-434 (2000).

4. Bresnen, M. and Marshall, N., "Motivation, commitment and the use of incentives in partnerships and alliances," Construction Management and Economics, Vol. 18, No. 5, pp. 587-598 (2000).

5. Brooke, K. L. and Litwin, G. H., "Mobilizing the partnering process," Journal of Management in Engineering, Vol. 13, pp. 42-48 (1997).

6. Bryman, A. and Cramer, D., Quantitative Data Analysis for Social Scientists, Routledge, New York (1990).

7. Byrne, B. M., Structural Equation Modeling with EQS and EQS/Windows: Basic Concepts, Applications and Programming, Sage, Thousand Oaks, CA (1994).

8. Chan, A. P. C., Chan, D. W. M., Chiang, Y. H., Tang, B. S., Chan, E. H. W., and Ho, K. S. K., "Exploring critical success factors for partnering in construction project," Journal of Construction Engineering and Management, Vol. 130, No. 2, pp. 188-198 (2004).

9. Cheng, E. W. L. and Li, H., "Construction partnering process and associated critical success factors: Quantitative investigation," Journal of Management in Engineering, Vol. 18, No. 4, pp. 194-202 (2002).

10. Cheng, E. W. L., Li, H., and Love, P. E. D., "Establishment of critical success factors for construction partnering," Journal of Management in Engineering, Vol. 16, No. 2, pp. 84-92 (2000).

11. Cheung, S. O., Ng, T. S. T., Wong, S. P., and Suen, H. C. H., "Behavioral aspects in construction partnering," International Journal of Project Management, Vol. 21, No. 5, pp. 333-343 (2003).

12. Chua, D. K. H., Kog, Y. C., and Loh, B. K., "Critical success factors for different project objectives," Journal of Construction Engineering and Management, Vol. 125, No. 3, pp. 142-150 (1999).

13. Construction Industry Institute (CII), In Search of Partnering Excellence, Special Publication No. 17-1, Rep., Partnering Task Force of CII, Austin, Tex (1991).

14. Ellison, S. D. and Miller, D. W., "Beyond ADR: Working toward synergistic strategic partnership," Journal of Management in Engineering, Vol. 11, pp. $44-54$ (1995).

15. Gay, L. R., Educational Research: Competencies for Analysis and Application, Merrill Prentice-Hall, Englewood Cliffs, N. J. (1996).

16. Haque, S. M. M., Green, R., and Keogh, W., "Collaborative relationships in the UK upstream oil and gas industry: Critical success and failure factors," Problems \& Perspectives in Management, Vol. 1, pp. 44-50 (2004).

17. Hoyle, R. H., "The structural equation modeling approach: Basic concepts and fundamental issues," in Hoyle, R. H. (ed.) Structural Equation Modeling: Concepts, Issues and Applications, Sage Publications, Thousand Oaks, CA, pp. 1-15 (1995).

18. Jöreskog, K. G. and Sörbom, D., LISREL 8: Structural Equation Model- 
ing with the SIMPLIS Command Language, Scientific Software International, Chicago (2002).

19. Lewis, J. D., Partnerships for Profit-Structuring and Managing Strategic Alliance, The Free Press, New York (1990).

20. Li, H., Cheng, E. W. L., and Love, P. E. D., "Partnering research in construction," Engineering, Construction and Architectural Management, Vol. 7, No. 1, pp. 76-92 (2000).

21. Li, H., Cheng, E. W. L., Love, P. E. D., and Irani, Z., "Co-operative benchmarking: A tool for partnering excellence in construction," International Journal of Project Management, Vol. 19, No. 3, pp. 171-179 (2001).

22. Lynch, R. P., "Building alliances to penetrate European markets," Journal of Business Strategy, Vol. 11, No. 2, pp. 4-8 (1990).

23. Mohr, J. and Spekman, R., "Characteristics of partnering success: Partnering attributes, communication behavior, and conflict resolution techniques," Strategic Management Journal, Vol. 15, No. 2, pp. 135-152 (1994).

24. Molenaar, K., Washington, S., and Diekmann, J., "Structural equation model of construction contract dispute potential," Journal of Construction Engineering and Management, Vol. 126, No. 4, pp. 268-277 (2000).

25. Norusis, M. J., SPSS 10.0 Guide to Data Analysis, Prentice Hall, Englewood Cliffs, New Jersey (2001).

26. Sarker, M. B., Aulakh, P. S., and Cavusgil, S. T., "The strategic role of relational bonding in inter-organizational collaborations: An empirical study of the global construction industry," Journal of International Management, Vol. 4, No. 2, pp. 415-421 (1998).

27. Sharma, S., Applied Multivariate Techniques, Wiley, New York, pp. 16123 (1996).

28. Stipanowich, T. J. and Matthews, W. L., "At the cutting edge: Conflict avoidance and resolution in the US construction industry," Construction Management and Economics, Vol. 15, pp. 505-512 (1997).

29. Thompson, P. J. and Sanders, S. R., "Partnering continuum," Journal of Management in Engineering, Vol. 14, pp. 73-78 (1998).

30. Wilson, R. A., Songer, A. D., and Diekmann, J., "Partnering: more than a workshop, a catalyst for change," Journal of Management in Engineering, Vol. 11, pp. 40-45 (1995). 